\title{
Functional switching of a native neuropeptide through interactions with pathogenic factors in dementia
}

\author{
Jiyeon $\mathrm{Han}^{1}$, Eunju Nam ${ }^{1}$, Jiwon Yoon ${ }^{2}$, Tongrui Qian ${ }^{3}$, Yulong Li, ${ }^{3,4,5}$, \\ Seung-Hee Lee ${ }^{2 *}$ and Mi Hee Lim $^{1 *}$
}

\footnotetext{
${ }^{1}$ Department of Chemistry, Korea Advanced Institute of Science and Technology (KAIST), Daejeon 34141, Republic of Korea

${ }^{2}$ Department of Biological Sciences, KAIST, Daejeon 34141, Republic of Korea

${ }^{3}$ State Key Laboratory Membrane Biology, Peking University School of Life Sciences, Beijing 100871, China

${ }^{4} \mathrm{PKU}-\mathrm{IDG} / \mathrm{McGovern}$ Institute for Brain Research, Beijing 100871, China

${ }^{5}$ Peking-Tsinghua Center for Life Sciences, Peking University, Beijing 100871, China

*To whom correspondence should be addressed: miheelim@kaist.ac.kr and shlee1@kaist.ac.kr
} 


\begin{abstract}
Impaired neurotransmission is linked to the progression of neurodegenerative disorders. The impact of pathogenic factors found in the diseases on the structures and functions of neurotransmitters has not been established, however. Here we report the discovery that the function of a native neuropeptide, somatostatin (SST), is switched through its conformational transition in the presence of metal ions, metal-free amyloid- $\beta(A \beta)$, and metal-bound $A \beta$ that are associated with toxicity observed in the brains of Alzheimer's disease patients. These pathological elements induce the self-assembly of SST and, consequently, prevent SST from binding to the receptor. In the reverse direction, SST modifies the aggregation profiles of A $\beta$ species in the absence and presence of metal ions and affects their cytotoxicity and interactions with cell membranes. Our work demonstrates both a loss of normal function and a gain of modulative function of SST under pathological conditions, which illuminates distinct activities of neurotransmitters towards neurodegenerative diseases.
\end{abstract}


Neurotransmitters are essential for signal transduction throughout whole nervous systems ${ }^{1-7}$. Neuronal communications accompanied by a variety of neurotransmitters, e.g., amino acids, small molecules, and metal ions, maintain the balance between excitatory and inhibitory synaptic transmission $2,3,5,6$. Upon being released from presynaptic neurons, neurotransmitters bind to postsynaptic receptors, including G-protein coupled receptors (GPCRs) or ligand-gated ion channels, subsequently initiating intracellular signalling pathways ${ }^{1,4}$. Given that synaptic dysfunction is closely related to the pathologies of neurodegenerative disorders such as Alzheimer's disease $(A D)^{1,8-11}$, the activities of neurotransmitters can be disrupted by pathogenic factors in diseased states.

In the AD-affected brain, senile plaques primarily composed of amyloid- $\beta(A \beta)$ aggregates and metal ions are found at the synaptic gap ${ }^{8,12,13} . A \beta$ is an intrinsically disordered peptide and tends to form aggregates, including oligomers and fibrils, as shown in Fig. $1 a^{14}$. Especially, soluble and structured oligomers are shown to be toxic ${ }^{14-16}$. The accumulation of highly concentrated metal ions into senile plaques causes metal ion dyshomeostasis and miscompartmentation leading to lowering the efficiency of neurotransmission and the activities of metalloenzymes ${ }^{17,18}$. Metal ions such as $\mathrm{Cu}(\mathrm{II})$ and $\mathrm{Zn}(\mathrm{II})$ are coordinated to $\mathrm{A} \beta$ producing metal-bound $\mathrm{A} \beta$ (metal-A $\beta$; Fig. 1a) that can generate and stabilize toxic structured $A \beta$ oligomers ${ }^{19-23}$. Furthermore, recent studies revealed the spatial overlap of senile plaques in the frontal cortex and hippocampus with somatostatin (SST; Fig. 1b), a neuropeptide that regulates the endocrine system and neurotransmission through GPCR-mediated signalling pathways ${ }^{24-28}$. SST was also reported to interact with $A \beta$ and metal ions, e.g., copper ${ }^{11,29-31}$, suggesting a link of SST to the amyloid cascade hypothesis and the metal ion hypothesis towards the pathology of $A D^{27,30,32}$. Despite these observations, the conformational and functional changes of SST in the presence of the pathological elements observed in the AD-affected brain, with its consequent impact on their properties, were unknown thus far.

We questioned whether SST is structurally and functionally changed under pathological conditions associated with $A D$ and such variations of SST can change the aggregation and cytotoxicity profiles of A $\beta$. Thus, the interactions of SST with metal ions, metal-free $A \beta$, and metal$A \beta$ and their influence on the conformational transition and GPCR binding of SST were determined at the molecular level. Moreover, we evaluated the effects of SST on the aggregation and toxicity of metal-free and metal-bound $A \beta$ species following its structural alteration. Overall, our studies validate a loss of normal function and a gain of modulative function of SST through direct contacts with the pathological elements found in $A D$, which illustrates the functional 
a

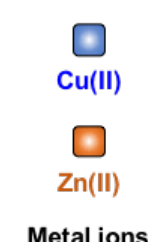

11

$\mathbf{A} \boldsymbol{\beta}_{40}$ : DAEFRHDSGYEVHHQKLVFFAEDVGSNKGAIIGLMVGGVV

$A \beta_{42}$ : DAEFRHDSGYEVHHQKLVFFAEDVGSNKGAIIGLMVGGVVIA
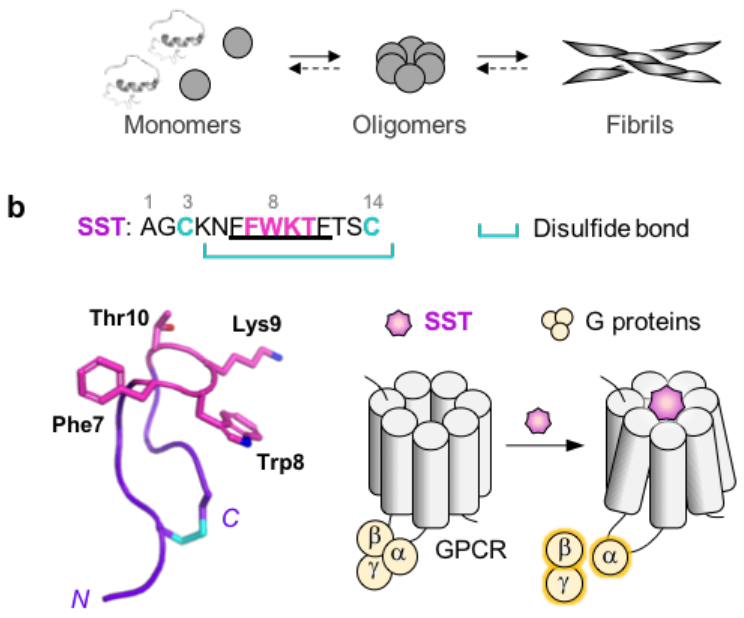

Fig. 1 | Pathogenic factors of AD and SST studied in this work. a, Metal ions, metal-free $A \beta$, and metal-A $\beta$ that are co-localized with SST in senile plaques. A $\beta$ tends to aggregate into oligomers and fibrils. Metal ions, e.g., $\mathrm{Cu}(\mathrm{II})$ and $\mathrm{Zn}(\mathrm{II})$, can generate and stabilize toxic $A \beta$ oligomers. b, Structure of SST determined by NMR spectroscopy (PDB $2 \mathrm{MI} 1^{33}$ ). The amino acid residues in a $\beta$-hairpin structure are underlined. The disulfide bond between Cys 3 and Cys 14 is indicated as a cyan line. The amino acid residues depicted in magenta are critical for SST binding to GPCR.

switching of the neurotransmitter upon the development of the disease.

\section{Results}

Metal binding of SST and its metal-induced aggregation. The binding of SST to $\mathrm{Cu}(\mathrm{II})$ and $\mathrm{Zn}(\mathrm{II})$ was first monitored by ultraviolet-visible (UV-Vis) and fluorescence spectroscopy. Upon incubation of SST with $\mathrm{Cu}(\mathrm{II})$, a new d-d transition band at ca. $590 \mathrm{~nm}$ was observed, indicative of $\mathrm{Cu}$ (II) coordination to SST (Supplementary Fig. 1a). This optical band was notably shifted to ca. $720 \mathrm{~nm}$ in the presence of a hexadentate chelator, EDTA (ethylenediaminetetraacetic acid), 
which is consistent with that of $\mathrm{Cu}(\mathrm{II})(\mathrm{EDTA})^{34}$. We further carried out fluorescence-quenching experiments ${ }^{35}$ to obtain the dissociation constant $\left(K_{d}\right)$ value of $\mathrm{Cu}(\mathrm{II})-\mathrm{SST}$. As depicted in Fig. 2a, the intrinsic fluorescence of SST was decreased by titrating various concentrations of $\mathrm{Cu}(\mathrm{II})$, indicating that the $K_{d}$ value for $\mathrm{Cu}(\mathrm{II})-\mathrm{SST}$ was determined to be $5.4( \pm 0.8) \mu \mathrm{M}$. It should be noted that this quenched fluorescence of SST was partially recovered by addition of EDTA (Supplementary Fig. 1b), which suggests that the change in emission is mainly driven by $\mathrm{Cu}(\mathrm{II})$ binding to SST. In the case of $\mathrm{Zn}$ (II) binding to SST, competitive binding studies were conducted employing Zincon (2-carboxy-2'-hydroxy-5'-sulfoformazyl-benzene monosodium salt) that is a colorimetric metal chelator with a 1:1 Zn(II)-to-ligand stoichiometry ${ }^{36}$. Upon titration of SST into $\mathrm{Zn}(\mathrm{II})$-Zincon, the absorbance at $618 \mathrm{~nm}$ was reduced, as shown in Fig. 2b, supporting the complexation of $\mathrm{Zn}(\mathrm{II})$ with SST over Zincon with the $K_{\mathrm{d}}$ value of $38.2( \pm 10.0) \mu \mathrm{M}$.

Moreover, we investigated a conformational change of SST upon binding to metal ions by circular dichroism (CD) spectroscopy and tricine-containing polyacrylamide gel electrophoresis (tricine-PAGE). As illustrated in Fig. 2c, our CD measurements exhibited that the random coil conformation in SST was mainly observed with a local minimum at ca. $200 \mathrm{~nm}$ in both the absence and presence of metal ions at an early incubation time point (e.g., $5 \mathrm{~min}$ ). In addition, a broad minimum at ca. $235 \mathrm{~nm}$ appeared notably in the sample of $\mathrm{Cu}$ (II)-added SST, which implies that $\mathrm{Cu}(\mathrm{II})$ binding of SST may trigger the exposure of the disulfide bond between Cys3 and Cys14 to aqueous media ${ }^{33,37,38}$. The random coil structure was still maintained under metal-free and $\mathrm{Zn}$ (II)present conditions even after $24 \mathrm{~h}$ incubation, but the structural rigidity of SST was enhanced in the presence of $\mathrm{Cu}(\mathrm{II})$. As displayed in Supplementary Fig. 1c, the addition of EDTA did not recover the decreased random coil conformation shown in $\mathrm{Cu}(\mathrm{II})$-added SST. These observations confirm the irreversible structural variation of SST upon binding to $\mathrm{Cu}(\mathrm{II})$.

In addition to the analysis of secondary structures, the size distribution of the resultant SST species was monitored by tricine-PAGE with Western blotting using an anti-SST antibody. As presented in Fig. 2d, a single band below $2 \mathrm{kDa}$ corresponding to monomeric SST (1.6 kDa) was detected up to $24 \mathrm{~h}$ incubation under both metal-free and $\mathrm{Zn}$ (II)-present conditions. Thus, metalfree and $\mathrm{Zn}$ (II)-added SST did not undergo the aggregation, which is consistent with the previous reports regarding $\mathrm{SST}^{33,39}$. Interestingly, the smearing in the gel was noticeably exhibited (<ca. $15 \mathrm{kDa}$ ) upon incubation of SST with $\mathrm{Cu}(\mathrm{II})$ for $8 \mathrm{~h}$ and $24 \mathrm{~h}$, indicative of the $\mathrm{Cu}(\mathrm{II})$-induced oligomerization of SST. Therefore, SST can bind to $\mathrm{Cu}(\mathrm{II})$ and $\mathrm{Zn}(\mathrm{II})$ in a micromolar range and, particularly, $\mathrm{Cu}(\mathrm{II})$ coordination to SST alters its secondary structure resulting in its oligomerization. 

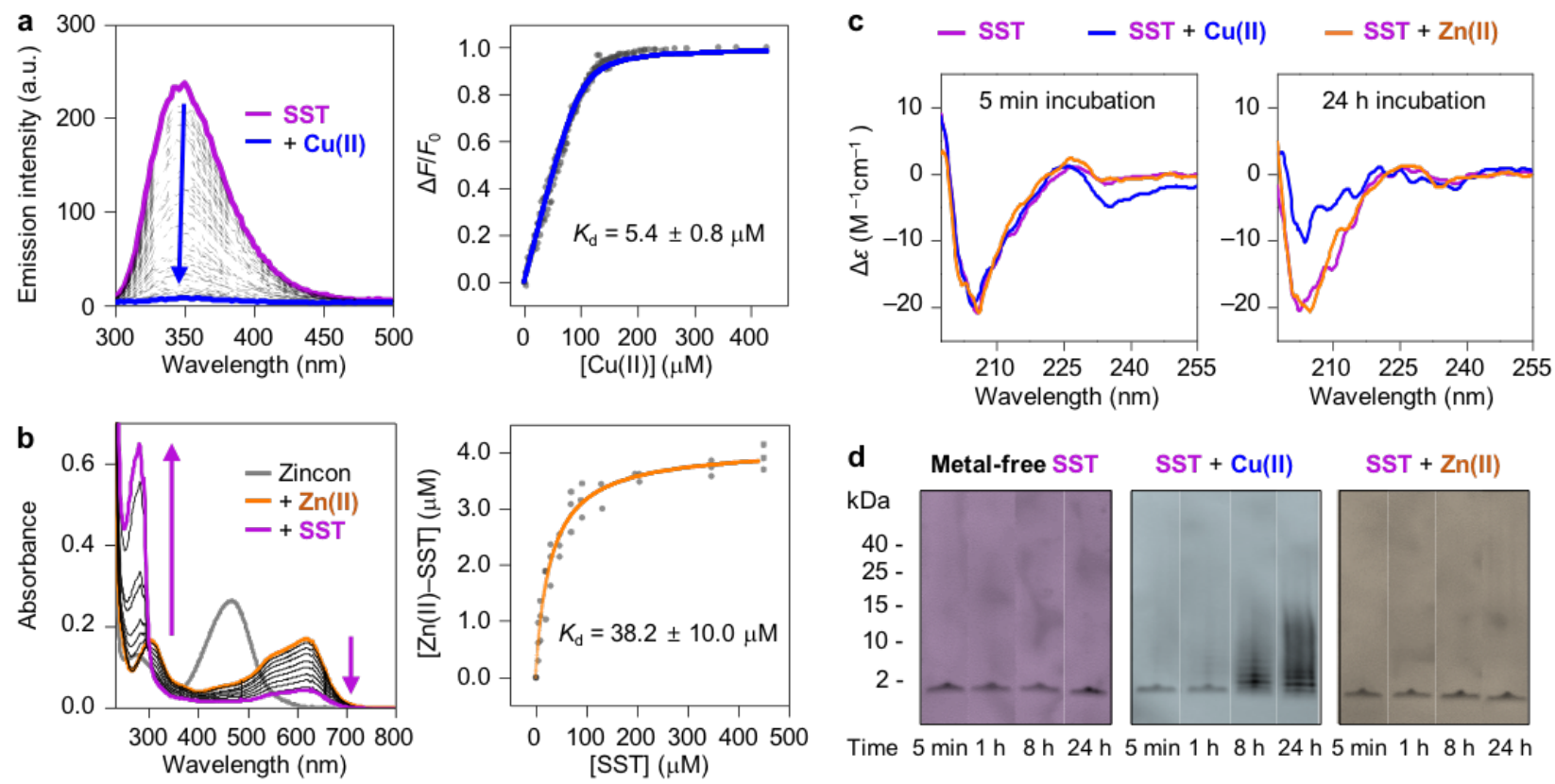

Fig. 2 | Metal-binding and conformational studies of SST. a, Fluorescence-based titration experiments to determine the $K_{d}$ value of $\mathrm{Cu}(\mathrm{II})$ against SST. Change in the intrinsic Trp fluorescence of SST was monitored upon titrating various concentrations of $\mathrm{Cu}(\mathrm{II})$. The $\Delta F / F_{0}$ values were fitted as a function of $[\mathrm{Cu}(\mathrm{II})]$ to estimate the $K_{\mathrm{d}}$ value for $\mathrm{Cu}(\mathrm{II})-\mathrm{SST}$. Conditions: $[\mathrm{SST}]=100 \mu \mathrm{M} ;[\mathrm{Cu}(\mathrm{II})]=100 \mu \mathrm{M}$ to $1 \mathrm{mM} ; 20 \mathrm{mM}$ HEPES, $\mathrm{pH}$ 7.4; room temperature; $\lambda_{\mathrm{ex}}=280$ $\mathrm{nm} ; \lambda_{\mathrm{em}}=300-500 \mathrm{~nm}$. Data are presented as mean \pm s.e.m. (standard error of the mean) of three independent experiments. b, Titration experiments detected by UV-Vis spectroscopy to obtain the $K_{d}$ value for $Z n(I I)-S S T$. A solution of SST was added into the solution containing Zincon and $\mathrm{Zn}(\mathrm{II})$. An orange curve was gained by fitting [Zn(II)-SST] as a function of [SST]. Conditions: [Zincon] = $10 \mu \mathrm{M}$; [Zn(II)] = $5 \mu \mathrm{M}$; [SST] = 5 to $450 \mu \mathrm{M} ; 20$ mM HEPES, pH 7.4; room temperature. Data are presented as mean \pm s.e.m. (standard error of the mean) of three independent experiments. c, Change in the secondary structure of SST in the absence and presence of metal ions monitored by $\mathrm{CD}$ spectroscopy. Conditions: [SST] $=100 \mu \mathrm{M} ;[\mathrm{M}(\mathrm{II})]=100$ $\mu \mathrm{M} ; 20 \mathrm{mM}$ HEPES, pH 7.4, $150 \mathrm{mM} \mathrm{NaF} ; 37^{\circ} \mathrm{C}$; constant agitation (250 rpm). d, Size distribution of the resultant SST species with or without metal ions probed by tricine-PAGE with Western blotting using an anti-SST antibody. The original gel images are depicted in Supplementary Fig. 2a,b (purple marks). Conditions: [SST] = $100 \mu \mathrm{M} ;[\mathrm{M}(\mathrm{II})]=100 \mu \mathrm{M} ; 20 \mathrm{mM}$ HEPES, pH 7.4, 150 $\mathrm{mM} \mathrm{NaCl} ; 37^{\circ} \mathrm{C}$; constant agitation $(250 \mathrm{rpm})$. All measurements were performed in triplicate. 
Receptor binding of SST incubated with metal ions. To identify whether metal binding to SST affects the interaction between SST and the receptor that initiates cellular signalling pathways ${ }^{27}$, we employed the genetically encoded GPCR-activation-based sensor (GRABsst; Fig. 3) that was recently developed by mimicking the binding profiles of a ligand to the GPCR ${ }^{40-42}$. The GRABsST sensor includes the circularly permutated green fluorescence protein (cpGFP) in a framework of the GPCRsst at the third intracellular loop. Upon activation of the GRABSST sensor, the fluorescence signal from cpGFP is increased through its conformational change, as illustrated in Fig. 3b. It should be noted that the effective concentration $\left(E_{50}\right)$ value of the GRABsst sensor against SST was measured to be $0.74( \pm 0.02) \mu \mathrm{M}$ under our experimental settings, as shown in Supplementary Fig. 3a, which is in a reliable range according to previously reported studies ${ }^{40-42}$. Moving forwards, we added SST treated with or without metal ions to HEK293T cells expressing

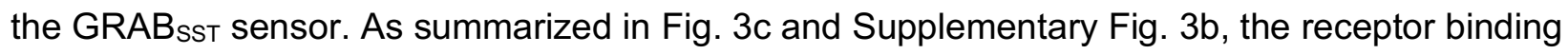
of SST was inhibited by ca. $22 \%$ with being incubated with $\mathrm{Cu}(\mathrm{II})$, compared to that of metal-free SST. In the case of $\mathrm{Zn}(\mathrm{II})$, the ability of SST to bind to the receptor was maintained. The control samples without SST exhibited no significant fluorescence (Supplementary Fig. 3c). These results substantiate a loss of normal function of SST in GPCR binding potentially through its aggregation mediated by $\mathrm{Cu}(\mathrm{II})$ binding (vide infra).

Given that the Phe7, Trp8, Lys9, and Thr10 residues in the $\beta$-hairpin conserved by the disulfide linkage between Cys3 and Cys 14, as depicted in Fig. 1b, are essential for the interaction between SST and $\mathrm{GPCR}_{\mathrm{SST}^{4}}{ }^{24,25}$, the microenvironment of this motif was further probed by measuring the Trp fluorescence of SST with and without metal ions. As indicated in Fig. 3d, the maximum fluorescence $\left(F_{\max }\right)$ of metal-free SST was lowered by ca. $25 \%$ after $24 \mathrm{~h}$ incubation. In the presence of $\mathrm{Cu}(\mathrm{II})$, the $F_{\max }$ value was reduced even at $5 \mathrm{~min}$ incubation, exhibiting an additional decrease in fluorescence by ca. $75 \%$ at $24 \mathrm{~h}$ incubation. Furthermore, $\mathrm{Cu}(\mathrm{II})$-treated SST presented a slight blue shift of the maximum wavelength $\left(\lambda_{\max }\right)$ by ca. $5 \mathrm{~nm}$ upon incubation from $5 \mathrm{~min}$ to $24 \mathrm{~h}$. Notably, changes in the $F_{\max }$ and $\lambda_{\max }$ values of $\mathrm{Cu}(\mathrm{II})$-treated SST were not restored by the addition of EDTA (Supplementary Fig. 1d). These observations suggest that $\mathrm{Cu}$ (II) binding to SST may modify the structural properties of SST with an increase in hydrophobicity around the motif responsible for GPCR binding ${ }^{43}$. As expected from the studies using the GRABsSt sensor, $\mathrm{Zn}$ (II) did not vary the fluorescence of SST. Overall, $\mathrm{Cu}$ (II) coordination to SST can interfere with the GPCR binding of SST via the conformational transition in its receptorinteracting region upon aggregation, which possibly leads to a loss of normal function towards GPCR-driven signalling pathways. 


\section{a}

SST \pm M(II) $\frac{\text { Various incubation time }}{37^{\circ} \mathrm{C} \text {, agitation }} \rightarrow \begin{gathered}\text { SST } \\ \text { species }\end{gathered} \rightarrow \begin{gathered}\text { c Treatment to d Fluorescence } \\ \text { the GRAB sensor measurement }\end{gathered}$

b
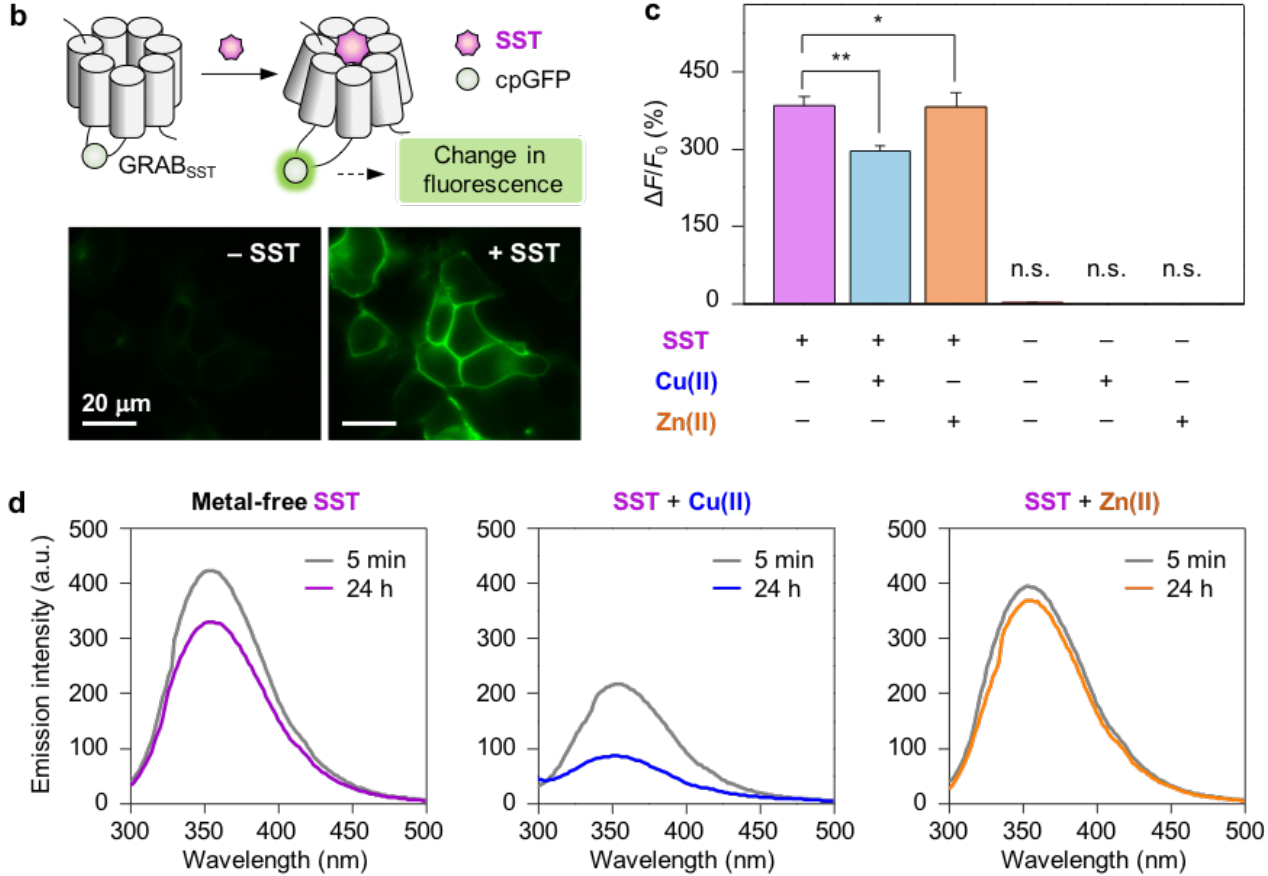

Fig. 3 | Alteration in the receptor binding of SST upon incubation with metal ions. a, Scheme of the experiments. $\mathbf{b}$, Live-cell imaging experiments against the GRAB ${ }_{S S T}$ sensor. Change in the fluorescence is correlated to the ability of SST species to bind to the receptor. c, Receptor binding of metal-free and metal-treated SST species measured by confocal microscopy. $\Delta F / F_{0}$ values were quantitatively analyzed after addition of the samples. The data sets are summarized in Supplementary Fig. 3. $\mathrm{n}=10-20 ;{ }^{*} P<0.05,{ }^{* *} P<0.01$, n.s., not significant; Kruskal-Wallis test with Bonferroni correction. Conditions: $\left[\mathrm{A} \beta_{40}\right]=0.5 \mu \mathrm{M}$; $[\mathrm{M}(\mathrm{II})]=0.5 \mu \mathrm{M}$; $[\mathrm{SST}]=0.5 \mu \mathrm{M}$. Scale bars $=20 \mu \mathrm{m}$. d, Change in the intrinsic Trp8 fluorescence upon incubation of metal-free and metal-added SST species. Conditions: [SST] = $100 \mu \mathrm{M}$; $[\mathrm{M}(\mathrm{II})]=100 \mu \mathrm{M} ; 20 \mathrm{mM}$ HEPES, pH 7.4, $150 \mathrm{mM} \mathrm{NaCl} ; 37^{\circ} \mathrm{C}$; constant agitation $(250 \mathrm{rpm}) ; \lambda_{\mathrm{ex}}=280 \mathrm{~nm} ; \lambda_{\mathrm{em}}=300-500 \mathrm{~nm}$. The measurements were performed in triplicate.

Effects of metal-A $\beta$ and metal-free $A \beta$ on the aggregation and receptor binding of SST. To verify the effects of $A \beta$ on the conformation and function of SST, we first analyzed the samples of SST $(1,638 \mathrm{Da})$ incubated with $A \beta_{40}(4,328 \mathrm{Da})$ or $A \beta_{42}(4,515 \mathrm{Da})$ in the absence and presence 
of metal ions by electrospray ionization-mass spectrometry (ESI-MS) (Fig. 4a,b and Supplementary Fig. 4). As displayed in Fig. 4b, in the presence of $\mathrm{Cu}(\mathrm{II})$, the new peaks appeared at $1,194 \mathrm{~m} / \mathrm{z}$ and $1,206 \mathrm{~m} / \mathrm{z}$ that are originated from +5 -charged species, in addition to $820 \mathrm{~m} / \mathrm{z}$ and $1,443 \mathrm{~m} / \mathrm{z}$ corresponding to monomeric $\mathrm{SST}^{2+}$ and $\mathrm{A}_{40}{ }^{3+}$, respectively. Under $\mathrm{Zn}(\mathrm{II})$-present and metal-free conditions, the +5 -charged peak at 1,194 $\mathrm{m} / \mathrm{z}$ was detected. To assign the aforementioned ions, we carried out tandem MS (ESI-MS ${ }^{2}$ ) by applying the collision-induced dissociation (CID) energy against the peak of interest, as presented in Fig. 4b and Supplementary Fig. 5. Our tandem MS studies revealed that the peak at 1,194 $\mathrm{m} / \mathrm{z}$ is composed of +2-charged SST and +3-charged A $\beta$, thus representing the formation of a hetero-dimer. More interestingly, the CID-associated fragmentation of the peak at 1,206 m/z indicated multiply charged SST and $A \beta_{40}$, both of which are bound to $\mathrm{Cu}(\mathrm{II})$. This implies the generation of a ternary complex comprised of SST, $C u(I I)$, and $A \beta_{40}$. In the case of $A \beta_{42}$, the interactions of SST towards $A \beta_{42}$ with and without metal ions were similar to those observed from $A \beta_{40}$ with and without metal ions (Supplementary Fig. 4).

To visualize the potential interactions between SST and A $\beta$, we performed docking studies employing the structures of the two peptides that were obtained by nuclear magnetic resonance (NMR) spectroscopy in an aqueous solution (for SST, PDB $2 \mathrm{MI}^{33}$; for A $\beta_{40}$, PDB $2 \mathrm{LFM}^{44}$ ). As illustrated in Fig. 4c, SST was positioned in the $N$-terminal region of $A \beta_{40}$, exhibiting multiple intermolecular interactions $(\Delta G=-11.6 \mathrm{kcal} / \mathrm{mol})$. Hydrogen bonds between SST and $A \beta_{40}$ were indicated: ( $\mathrm{i}$ and ii) the backbone carbonyl group of Cys3 in SST and the backbone amide moiety of His6 or Asp7 in A $\beta_{40}$; (iii) the backbone amide group of Asn5 in SST and the side chain of Ser8 in $A \beta_{40}$; (iv) the side chain amide moiety of Asn5 in SST and the backbone carbonyl group of Ser8 in $A \beta_{40}$. In addition, $\pi-\pi$ stacking of Phe6 in SST and Tyr10 in A $\beta_{40}$ was observed. It should be noted that other conformers with the $\Delta G$ values less than $-11.0 \mathrm{kcal} / \mathrm{mol}$ were also analyzed and summarized in Supplementary Fig. 6.

We further probed the effects of metal-A $\beta$ and metal-free $A \beta$ on the aggregation of SST by tricine-PAGE with Western blotting using an anti-SST antibody. As depicted in Fig. 4d, the sample of SST presented the enhanced smearing larger than $10 \mathrm{kDa}$ in the gel by incubation with $\mathrm{Cu}(\mathrm{II})-$ $A \beta_{40}$ for $8 \mathrm{~h}$ and $24 \mathrm{~h}$. Thus, $\mathrm{Cu}(\mathrm{II})-\mathrm{A} \beta_{40}$ could induce the production of SST oligomers. In the case of $\mathrm{Zn}(\mathrm{II})-\mathrm{A} \beta_{40}$ and metal-free $A \beta_{40}$, SST aggregates in a range from $5 \mathrm{kDa}$ to $15 \mathrm{kDa}$ were formed after $8 \mathrm{~h}$ and $24 \mathrm{~h}$ treatment. To evaluate the stability of the resultant SST aggregates, we additionally conducted sodium dodecyl sulfate (SDS)-PAGE of the samples pre-treated with urea . As indicated in Fig. 4e, the size of the SST aggregates produced 
a

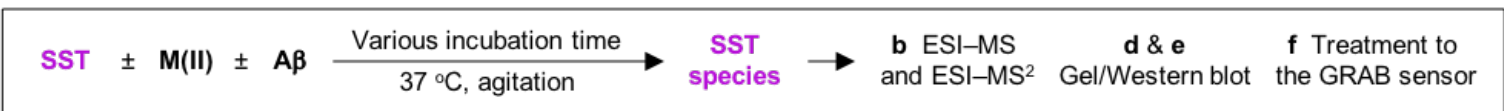

b OSST OA $\boldsymbol{\beta}_{40} \quad C\left[\mathrm{SST}+\mathbf{A} \boldsymbol{\beta}_{40}\right] \quad Q\left[\mathrm{SST}+\mathrm{Cu}(\mathrm{II})+\mathbf{A} \boldsymbol{\beta}_{40}\right] \quad \sigma\left[\mathbf{A} \boldsymbol{\beta}_{40}+\mathrm{Cu}(\mathrm{II})\right]$
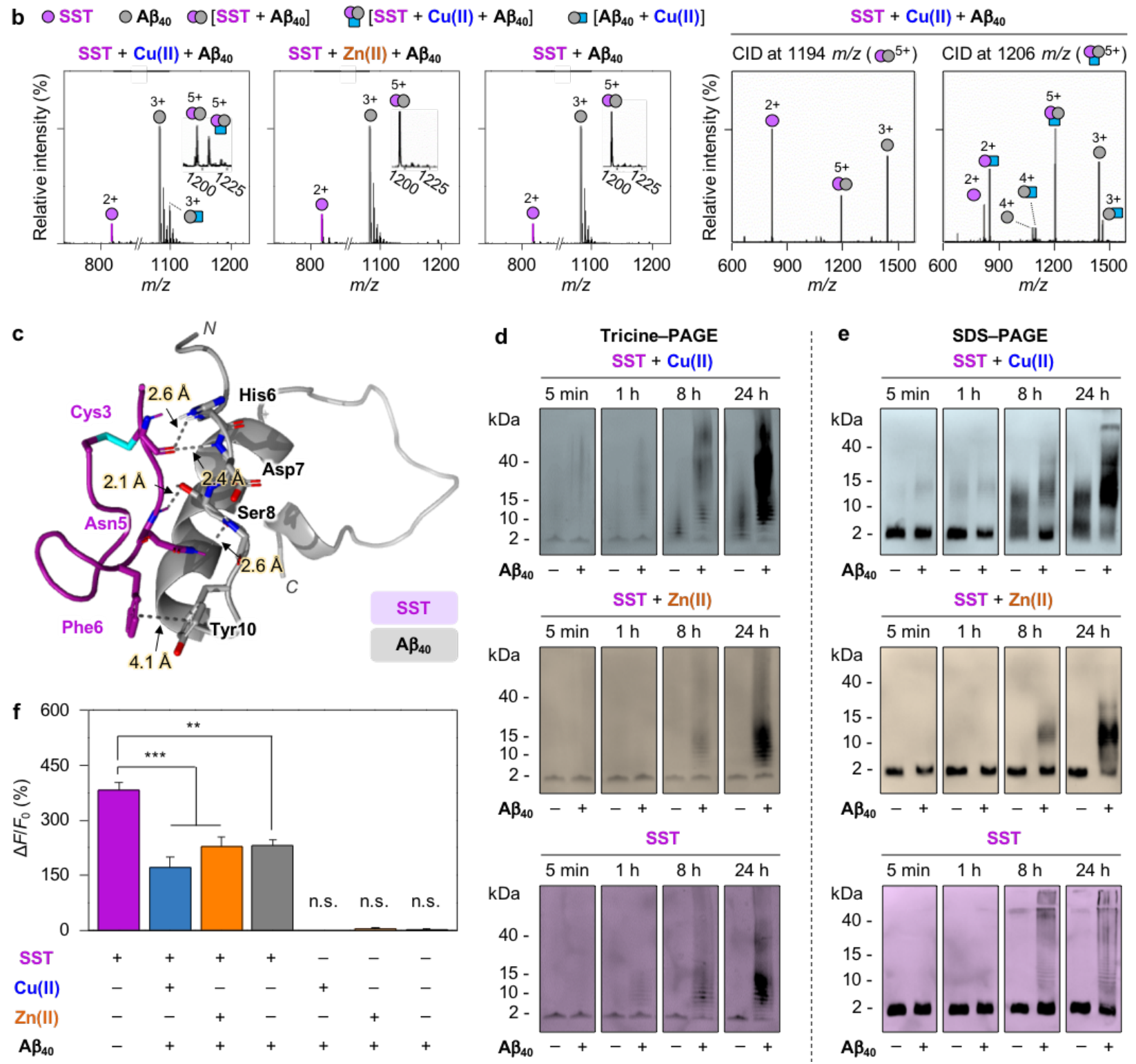

Fig. 4 | Influence of metal-A $\beta$ and metal-free $A \beta$ on the aggregation of SST. a, Scheme of the experiments. $\mathbf{b}$, SST binding to $A \beta_{40}$ with and without metal ions monitored by ESI-MS and ESI-MS ${ }^{2}$. SST and $A \beta_{40}$ are presented with purple and gray circles, respectively. $\mathrm{Cu}(\mathrm{II})$ is indicated as a blue rectangle. It should be noted that $\mathrm{Zn}(\mathrm{II})$-bound $A \beta_{40}$ monomer was not observed under our experimental conditions. The peaks corresponding to $\left[S S T+A \beta_{40}\right]^{5+}$ and $[S S T$ $\left.+\mathrm{Cu}(\mathrm{II})+\mathrm{A} \beta_{40}\right]^{5+}$, found in the sample containing SST, $\mathrm{Cu}(\mathrm{II})$, and $\mathrm{A} \beta_{40}$, were further characterized 
by ESI-MS ${ }^{2}$. The ESI-MS ${ }^{2}$ analysis of the samples containing SST and A $\beta_{40}$ with or without $\mathrm{Zn}$ (II) is summarized in Supplementary Fig. 5. Charge states are marked above the peaks in the MS spectra. Conditions: [SST] $=100 \mu \mathrm{M} ;[\mathrm{M}(\mathrm{II})]=100 \mu \mathrm{M} ;\left[\mathrm{A} \beta_{40}\right]=100 \mu \mathrm{M} ; 20 \mathrm{mM}$ ammonium acetate; $37^{\circ} \mathrm{C}$; incubation for $3 \mathrm{~h}$; constant agitation (250 rpm). The measurements were conducted in triplicate. The samples were diluted by 10 fold before injection to the mass spectrometer. c, Possible interactions between SST (PDB 2MI1 ${ }^{33}$ ) with $\mathrm{A} \beta_{40}\left(\mathrm{PDB} 2 \mathrm{LFM}^{44}\right.$ ) visualized by docking studies. SST and $A \beta_{40}$ are depicted in purple and gray, respectively. The dashed lines indicate possible hydrogen bonds (within $3.0 \AA$ ) and $\pi-\pi$ interactions (within $4.5 \AA$ ) between the two peptides. d,e, Size distribution of the resultant SST species with and without $A \beta$ probed by gel/Western blot with an anti-SST antibody. Conditions: [SST] $=100 \mu \mathrm{M} ;[\mathrm{M}(\mathrm{II})]=100 \mu \mathrm{M} ;\left[\mathrm{A} \beta_{40}\right]$ $=100 \mu \mathrm{M} ; 20 \mathrm{mM}$ HEPES, $\mathrm{pH} 7.4,150 \mathrm{mM} \mathrm{NaCl} ; 37^{\circ} \mathrm{C}$; constant agitation (250 rpm). The measurements were performed in triplicate. The original gel images are depicted in Supplementary Fig. 2a. f, Receptor binding of SST species incubated with $A \beta$ measured by confocal microscopy. The data sets are summarized in Supplementary Fig. 8. $\mathrm{n}=21-23$; ${ }^{* *} P<$ $0.01,{ }^{* * *} P<0.001$; n.s., not significant; Kruskal-Wallis test with Bonferroni correction. Conditions: $\left[\mathrm{A} \beta_{40}\right]=0.5 \mu \mathrm{M} ;[\mathrm{M}(\mathrm{II})]=0.5 \mu \mathrm{M} ;[\mathrm{SST}]=0.5 \mu \mathrm{M}$.

with $\mathrm{Cu}(\mathrm{II})-\mathrm{A} \beta_{40}$ and $\mathrm{Zn}(\mathrm{II})-\mathrm{A} \beta_{40}$ was mainly between $10 \mathrm{kDa}$ and $15 \mathrm{kDa}$, and these aggregates were relatively resistant to SDS. Distinctly, in the case of SST aggregates formed with metal-free $A \beta_{40}$, the smearing larger than $5 \mathrm{kDa}$ was weakened with a relatively prominent band below 2 $\mathrm{kDa}$, which presents the different stability of SST oligomers under metal-absent conditions. In a similar trend to $A \beta_{40}$, SST was observed to aggregate in the presence of metal-A $\beta_{42}$ and metalfree $A \beta_{42}$, as illustrated in Supplementary Fig. 7. The SST aggregates generated by metal-A $\beta_{42}$ and metal-free $A \beta_{42}$ showed the smearing bands larger than ca. $10 \mathrm{kDa}$ in SDS-PAGE, indicating relatively stable oligomers against SDS. Together, metal-A $\beta$ and metal-free $A \beta$ can trigger the aggregation of SST to different degrees.

Lastly, we verified the ability of the SST aggregates generated with $A \beta$ species to bind to the receptor through live-cell imaging employing the GRABSST sensor. We incubated SST with $A \beta_{40}$ in the absence and presence of metal ions for $24 \mathrm{~h}$ followed by addition to HEK293T cells expressing the GRABsst sensor. As shown in Fig. 4f and Supplementary Fig. 8a, SST treated with metal-A $\beta_{40}$ or metal-free $A \beta_{40}$ could not bind to the receptor by $40-55 \%$, relative to SST 
only. It should be noted that $A \beta_{40}$ with and without metal ions did not affect the fluorescence of the GRAB ${ }_{S S T}$ sensor (Supplementary Fig. 8b), consistent with the previous study reporting no uptake of $A \beta$ species into HEK293T cells ${ }^{45}$. This observation can exclude the possibility of $A \beta$ to sterically block the SST-binding site in the GRABSST sensor. Collectively, our studies demonstrate that both metal-A $\beta$ and metal-free $A \beta$ provoke the aggregation of SST to different extents and disrupt its GPCR binding.

Impact of SST on metal-induced and metal-free $A \boldsymbol{\beta}$ aggregation. We examined the impact of SST on the aggregation of metal-A $\beta$ and metal-free $A \beta$, as illustrated in Fig. 5 and Supplementary Figs. 9 and 10. The aggregation kinetics of $A \beta$ was traced with and without metal ions by the thioflavin-T (ThT) assay that is used for quantifying the amount of $\beta$-sheet-rich peptide species ${ }^{46}$. As displayed in Fig. 5b, in the absence of SST, $\mathrm{Cu}(\mathrm{II})-\mathrm{A} \beta_{42}$ and $\mathrm{Zn}(\mathrm{II})-\mathrm{A} \beta_{42}$ reached the plateau at $1 \mathrm{~h}$ and $4 \mathrm{~h}$, respectively. Particularly, the fluorescence intensity of $\mathrm{Cu}(\mathrm{II})-\mathrm{A} \beta_{42}$ was decreased by ca. $20 \%$ after the plateau possibly because of the precipitation or the formation of ThTunreactive species. Upon incubation of 1 equiv of SST with metal-A $\beta_{42}$, the ThT fluorescence was indicated to be greater than that of metal-A $\beta_{42}$ without SST. Furthermore, the aggregation kinetics of metal-A $\beta_{42}$ was identified in the presence of sub- and supra-equimolar concentrations of SST, as presented in Supplementary Fig. 9a. The ThT emission intensity of metal-A $\beta_{42}$ with SST was increased in a concentration-dependent manner, manifesting the effect of SST on the generation of $\beta$-sheet-rich metal-A $\beta_{42}$ aggregates. In the case of metal-free $A \beta_{42}$, the fluorescence was slightly changed even with 5 equiv of SST, compared to that incubated with 0.5 and 1 equiv of SST (Fig. 5b and Supplementary Fig. 9a). As shown in Supplementary Fig. 9b, the $t_{1 / 2}$ values for the aggregation of metal-A $\beta_{42}$ and metal-free $A \beta_{42}$ were analyzed, where $t_{1 / 2}$ is the half-time when the fluorescence intensity reaches $50 \%$ of its maximum value. Based on the calculated $t_{1 / 2}$ values, the overall aggregation kinetics of metal-A $\beta_{42}$ was delayed by SST, while the aggregation of metal-free $A \beta_{42}$ with SST was not significantly affected. In the case of $\mathrm{Cu}(\mathrm{II})-\mathrm{A} \beta_{40}$ and $\mathrm{Zn}(\mathrm{II})-$ A $\beta_{40}$, SST could reduce the amount of the ThT-reactive species through the elongation phase and the plateau, respectively, as described in Supplementary Fig. 10b. The influence of SST on the aggregation of metal-A $\beta_{40}$ was also dependent on its stoichimetry to metal-A $\beta_{40}$ (Supplementary Fig. 9c). The $t_{1 / 2}$ value for $\mathrm{Cu}(\mathrm{II})-\mathrm{A} \beta_{40}$ aggregation upon treatment of SST was shortened, while that for $\mathrm{Zn}(\mathrm{II})-\mathrm{A} \beta_{40}$ aggregation was moderately increased (Supplementary Fig. 9d). In addition, the ThT fluorescence and the $t_{1 / 2}$ values for metal-free $A \beta_{40}$ aggregation were not notably modified 

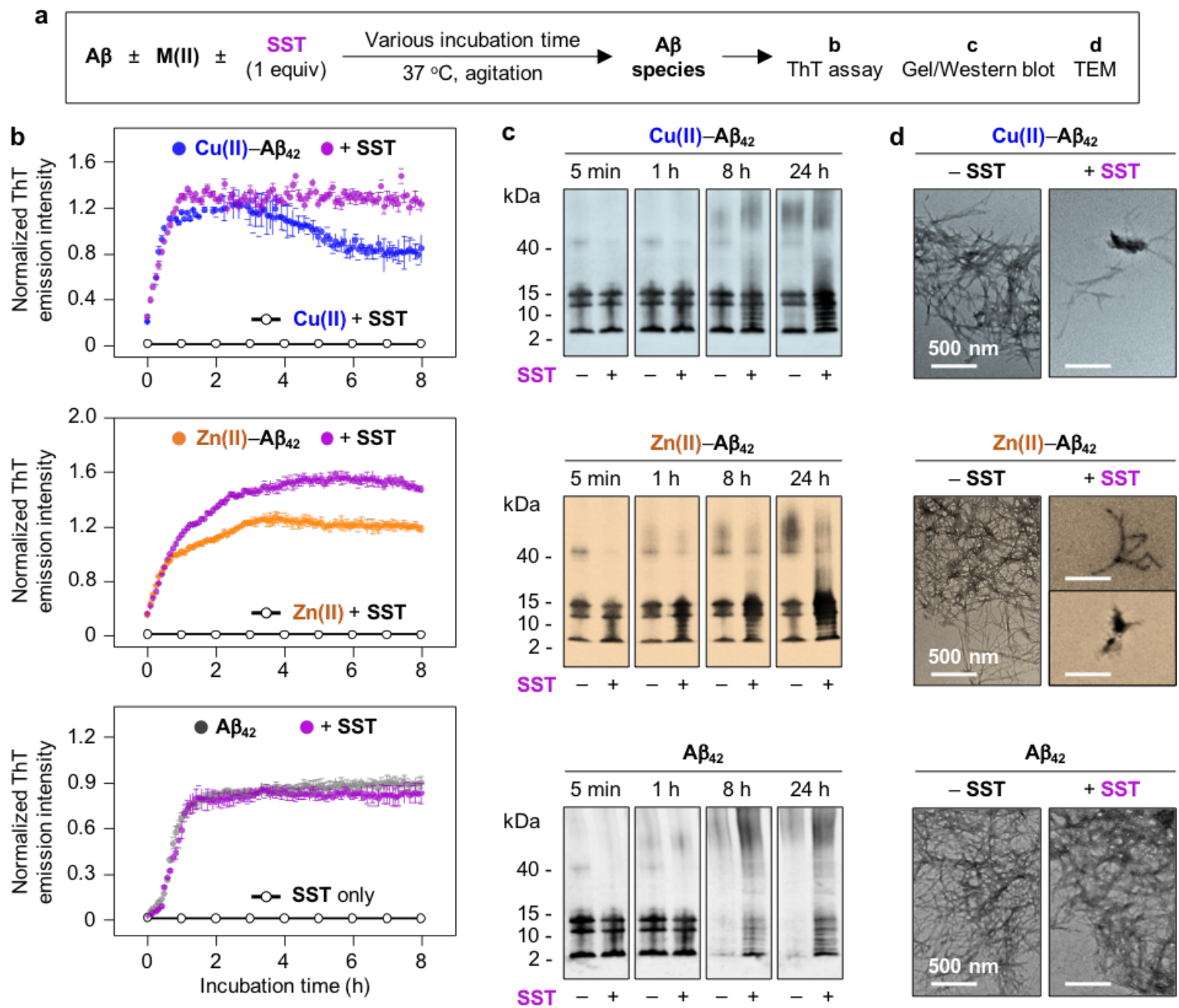

Fig. 5 | Effects of SST on metal-induced and metal-free $\mathbf{A} \beta$ aggregation. a, Scheme of the aggregation studies. $\mathbf{b}$, Aggregation kinetics of metal-A $\beta_{42}$ and metal-free $A \beta_{42}$ species upon treatment of SST analyzed by the ThT assay. Conditions: $\left[\mathrm{A} \beta_{42}\right]=20 \mu \mathrm{M} ;[\mathrm{Cu}(\mathrm{II})]=18 \mu \mathrm{M} ;[\mathrm{Zn}(\mathrm{II})]$ $=20 \mu \mathrm{M} ;[\mathrm{SST}]=20 \mu \mathrm{M} ;[\mathrm{ThT}]=20 \mu \mathrm{M} ; 20 \mathrm{mM}$ HEPES, $\mathrm{pH} 7.4,150 \mathrm{mM} \mathrm{NaCl} ; 37^{\circ} \mathrm{C}$; constant agitation $(250 \mathrm{rpm}) ; \lambda_{\mathrm{ex}}=440 \mathrm{~nm} ; \lambda_{\mathrm{em}}=490 \mathrm{~nm}$. Data are presented as mean \pm s.e.m. (standard error of the mean) of three independent experiments. c, Size distributions of the resultant metal$A \beta_{42}$ and metal-free $A \beta_{42}$ species monitored by tricine-PAGE with Western blotting using an anti$A \beta$ antibody (6E10). The original gel images are depicted in Supplementary Fig. 2d. Conditions: $\left[\mathrm{A} \beta_{42}\right]=100 \mu \mathrm{M} ;[\mathrm{M}(\mathrm{II})]=100 \mu \mathrm{M} ;[\mathrm{SST}]=100 \mu \mathrm{M} ; 20 \mathrm{mM}$ HEPES, $\mathrm{pH}$ 7.4, $150 \mathrm{mM} \mathrm{NaCl} ; 37^{\circ} \mathrm{C}$; constant agitation (250 rpm). d, Morphologies of the resultant peptide aggregates detected by TEM. Conditions: $\left[\mathrm{A} \beta_{42}\right]=100 \mu \mathrm{M}$; $[\mathrm{M}(\mathrm{II})]=100 \mu \mathrm{M}$; $[\mathrm{SST}]=100 \mu \mathrm{M} ; 20 \mathrm{mM} \mathrm{HEPES}, \mathrm{pH}$ 7.4, 150 $\mathrm{mM} \mathrm{NaCl} ; 37^{\circ} \mathrm{C}$; constant agitation $(250 \mathrm{rpm}$ ). Scale bars $=500 \mathrm{~nm}$. All measurements were 
performed in triplicate.

by incubation with sub- and supra-equimolar amounts of SST. It should be noted that no significant fluorescence was observed from the samples containing SST with or without metal ions under our experimental conditions. Overall, SST can vary the aggregation kinetics of A $\beta$ species, more noticeably in the presence of metal ions.

Next, the molecular weight distributions of $A \beta$ upon incubation with SST were determined by tricine-PAGE using an anti-A $\beta$ antibody (6E10) that can detect the $N$-terminal region of $A \beta^{47}$. As shown in Fig. $5 \mathrm{c}$, in the absence of SST, $A \beta_{42}$ oligomers below $15 \mathrm{kDa}$, including trimers and tetramers, were observed at early incubation time points under metal-present conditions. In contrast, such oligomeric species disappeared after $8 \mathrm{~h}$ incubation. Upon treatment of SST with metal-A $\beta_{42}$ and metal-free $A \beta_{42}$ for $8 \mathrm{~h}$ and $24 \mathrm{~h}$, the smearing in the gels between $4 \mathrm{kDa}$ and 15 kDa was monitored, indicative of forming multiple oligomers composed of either $A \beta_{42}$, SST, or both with and without metal ions. These observations regarding the intermolecular interactions between SST and $A \beta_{42}$ oligomers in the absence and presence of metal ions were supported by the ESI-MS studies, as depicted in Supplementary Fig. 11. The resultant peptide aggregates that are too large to penetrate the gel matrix were detected by transmission electron microscopy (TEM). As displayed in Fig. $5 d$, the morphology of the $A \beta_{42}$ aggregates produced with metal ions and SST was indicated to be a mixture of shorter fibrils and amorphous aggregates, compared to branched fibrils shown in the SST-free metal-A $\beta_{42}$ aggregates. No morphological change of metal-free $A \beta_{42}$ incubated with SST was indicated, relative to that without SST, exhibiting large and branched fibrils. The effect of SST on the molecular weight distiribution of metal-A $\beta_{40}$ upon aggregation was less, but smaller fibrils of metal-A $\beta_{40}$ were produced in the presence of SST, probed by tricine-PAGE and TEM, respectively (Supplementary Fig. 10c,d). Compared to metal$A \beta_{40}$, the smearing band of metal-free $A \beta_{40}$ was vanished with treatment of SST, exhibiting the formation of amorphous aggregates. The different reactivity of SST with $A \beta_{42}$ over $A \beta_{40}$ may result from the distinct distribution and conformations of $A \beta$ aggregates (particularly, oligomers) upon aggregation $^{48,49}$. These overall observations corroborate that SST significantly modifies the aggregation of metal-A $\beta$, which demonstrates a gain of modulative function of SST under pathogenic conditions.

Cytotoxicity of metal-A $\beta$ and metal-free $A \beta$ treated with SST. A $\beta$ species can interact with cell membranes and, consequently, cause cytotoxicity through multiple pathways such as blocking 
cellular receptors and forming ion channels ${ }^{14,50,51}$. Thus, we investigated the effects of SST on the cytotoxicity induced by metal-A $\beta$ and metal-free $A \beta$ as well as the $A \beta$-cell membrane interaction. As displayed in Fig. 6a, SST pre-incubated with A $\beta$ in the absence and presence of metal ions was introduced to human neuroblastoma SH-SY5Y cells, reported to uptake $A \beta$ species ${ }^{45}$, and the cell viability was measured by the MTT assay [MTT = 3-(4,5-dimethylthiazol-2-yl)-2,5diphenyltetrazolium bromide]. $\mathrm{Cu}(\mathrm{II})-\mathrm{A} \beta_{42}$ and $\mathrm{Zn}(\mathrm{II})-\mathrm{A} \beta_{42}$ incubated with SST improved cell

a
$A \beta \pm M(I I) \pm S S T$
$\underset{24}{27^{\circ} \mathrm{C} \text {, agitation }}$
Peptide
species
b
Cell viability Immunocytochemistry
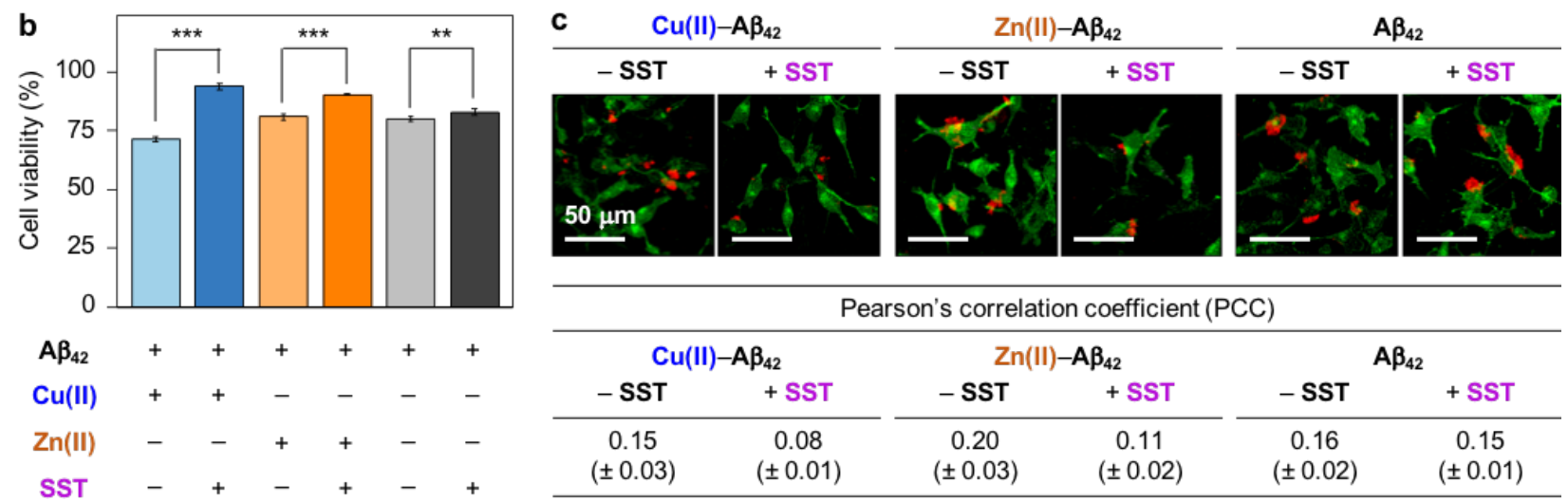

\begin{tabular}{|c|c|c|c|c|c|}
\hline \multicolumn{6}{|c|}{ Pearson's correlation coefficient (PCC) } \\
\hline \multicolumn{2}{|c|}{$\mathrm{Cu}(\mathrm{II})-\mathbf{A} \boldsymbol{\beta}_{42}$} & \multicolumn{2}{|c|}{$\mathrm{Zn}(\mathrm{II})-\mathbf{A} \boldsymbol{\beta}_{42}$} & \multicolumn{2}{|c|}{$\mathbf{A} \boldsymbol{\beta}_{42}$} \\
\hline - SST & + SST & - SST & + SST & - SST & + SST \\
\hline $\begin{array}{c}0.15 \\
( \pm 0.03)\end{array}$ & $\begin{array}{c}0.08 \\
( \pm 0.01)\end{array}$ & $\begin{array}{c}0.20 \\
( \pm 0.03)\end{array}$ & $\begin{array}{c}0.11 \\
( \pm 0.02)\end{array}$ & $\begin{array}{c}0.16 \\
( \pm 0.02)\end{array}$ & $\begin{array}{c}0.15 \\
( \pm 0.01)\end{array}$ \\
\hline
\end{tabular}

Fig. 6 | Impact of SST on the cytotoxicity mediated by metal-A $\beta$ and metal-free A $\beta$. a, Scheme of the cell studies. b, Survival of the cells treated with $A \beta_{42}$ and SST with or without metal ions. Cell viability, determined by the MTT assay, was calculated in comparison to that with an equivalent amount of the buffered solution (20 mM HEPES, pH 7.4, $150 \mathrm{mM} \mathrm{NaCl}$ ). Conditions: $\left[\mathrm{A} \beta_{42}\right]=10 \mu \mathrm{M} ;[\mathrm{M}(\mathrm{II})]=10 \mu \mathrm{M} ;[\mathrm{SST}]=10 \mu \mathrm{M}$. ${ }^{* *} P<0.01,{ }^{* * *} P<0.001$; Student's $t$-test. Data are presented as mean \pm s.e.m. (standard error of the mean) of three independent experiments. c, Live-cell localization of $A \beta_{42}$ incubated with SST. The cell membrane was stained by a green fluorescence membrane dye followed by immunoblotting $A \beta$ species using an anti-A $\beta$ antibody (6E10) and the Alexa Fluor 647-goat anti-mouse secondary antibody. PCCs were calculated to present the degree on overlapping the green and red fluorescence signals. The bright-field images are presented in Supplementary Fig. 13. Conditions: $\left[\mathrm{A} \beta_{42}\right]=10 \mu \mathrm{M} ;[\mathrm{M}(\mathrm{II})]=10 \mu \mathrm{M}$; [SST] $=10 \mu \mathrm{M}$. Scale bars $=50 \mu \mathrm{m}$. Data are presented as mean \pm s.e.m. (standard error of the mean) of three independent experiments. 
survival by ca. $20 \%$ and $10 \%$, respectively (Fig. 6b). As expected from the aggregation studies (vide supra), SST could not significantly affect the cytotoxicity triggered by metal-free $A \beta_{42}$. The cytotoxicity of metal-A $\beta_{40}$ and metal-free $A \beta_{40}$ was not altered even with incubation of SST, as presented in Supplementary Fig. 12.

To identify a relationship between the decrease in the cytotoxicity of $\mathrm{Cu}(\mathrm{II})-\mathrm{A} \beta_{42}$ and $\mathrm{Zn}(\mathrm{II})-$ $A \beta_{42}$ by SST and their interactions with cell membranes, we carried out immunocytochemistry studies. After treatment of metal-A $\beta$ and metal-free $A \beta$ added with or without SST to living cells, cytoplasmic membranes were stained by a fluorescent membrane dye, CellBrite green ${ }^{45,52}$, followed by immunoblotting $A \beta$ species using an anti-A $\beta$ antibody (6E10) and the Alexa Fluor 647goat anti-mouse secondary antibody, as illustrated in Fig. 6c and Supplementary Figs. 13 and 14. When $A \beta$ species are positioned on the cellular surface, the green and red fluorescence signals are overlapped ${ }^{52}$. To quantitatively analyze the interaction between $A \beta$ species and cell membranes, the Pearson's correlation coefficient (PCC), indicative of the degree of the overlap between the two fluorophores, was calculated. A PCC value greater than zero represents a positive linear relationship between the two different variables. The PCC values for the species of $\mathrm{Cu}(\mathrm{II})-\mathrm{A} \beta_{42}$ and $\mathrm{Zn}(\mathrm{II})-\mathrm{A} \beta_{42}$ are $0.15( \pm 0.03)$ and $0.20( \pm 0.03)$, respectively, as shown in Fig. 6c. These values were noticeably reduced by ca. $50 \%$ upon incubation of SST $[0.08( \pm 0.01)$ and 0.11 ( \pm 0.02 ), respectively], implying the decreased interaction between cell membranes and metal-A $\beta_{42}$ species produced with SST. The localization of metal-free $A \beta_{42}$ species was not modified even after addition of SST, exhibiting a similar PCC value to that without SST. As summarized in Supplementary Fig. 14, the PCC values for the species of metal-A $\beta_{40}$ and metalfree $A \beta_{40}$ with or without SST were almost identical. This observation suggests that SST could not change the strength of the interactions between $A \beta_{40}$ species and cell membranes in both the absence and presence of metal ions. Thus, SST diminishes the interaction between $A \beta_{42}$ species and cell membranes under metal-present conditions. Together, SST can attenuate the cytotoxicity induced by metal-A $\beta_{42}$ through suppressing the $A \beta$-cell membrane interaction. This confirms a gain of modulative function of SST against the cytotoxicity triggered by $A \beta$, notably in the presence of metal ions.

\section{Discussion}

Impaired neurotransmission is associated with cognitive decline upon the progression of $A^{7-9,28}$. Misfolded $A \beta$ aggregates found in the $A D$-affected brain can cause synaptic dysfunction: (i) blocking the receptors; (ii) aberrantly releasing neurotransmitters; (iii) trapping neurotransmitters 
into senile plaques at the synaptic cleft $^{11,45,51,53}$. To date, the mechanisms of how direct interactions with pathogenic factors can alter the structures and functions of neurotransmitters were unknown. This work is the first report to illustrate a loss of normal function and a gain of modulative function of a native neurotransmitter, SST, through intermolecular interactions with the pathogenic elements in $A D$, including metal ions, metal-A $\beta$, and metal-free $A \beta$, with its subsequent conformational transition, to the best of our knowledge.

Our studies demonstrate that the interactions of SST with $\mathrm{Cu}(\mathrm{II}), \mathrm{Cu}(\mathrm{II})-\mathrm{Zn}(\mathrm{II})-\mathrm{A} \beta$, and metal-free $A \beta$ can direct its self-assembly. $\mathrm{Cu}(\mathrm{II})$ binding to SST decreases its random coil structure and exposes the disulfide bond between Cys3 and Cys14 to aqueous media, accompanied by an increase in hydrophobicity at the region responsible for GPCR binding. In the case of A $\beta$, SST forms a hetero-dimer and a ternary complex in the absence and presence of metal ions, respectively, with the subsequent induction of SST aggregation. The ability of the SST aggregates produced by $\mathrm{Cu}(\mathrm{II})$, metal-A $\beta$, and metal-free $A \beta$ to bind to the GPCR is lower than monomeric SST in living cells. Thus, SST is conformationally changed and, consequently, loses its normal function under pathological conditions. In a reverse direction, SST noticeably controls the aggregation properties of metal-A $\beta$ and the morphology of the resultant aggregates. Moreover, the effects of SST towards metal-A $\beta_{42}$ can disrupt the interaction between the resultant metal$A \beta_{42}$ aggregates and cellular membranes leading to the improvement of their cytotoxicity. These observations support that a gain of modulative function of SST towards the aggregation and toxicity profiles of metal-A $\beta$. Clearly, our studies demonstrate that the structures and activities of SST are variable depending on the conditions, which provides broader insight into how neurotransmitters are involved in the pathologies of neurodegenerative diseases.

\section{Methods}

Materials and methods. All chemical reagents were purchased from commercial suppliers and used as received unless otherwise stated. Synthetic SST (AGCKNFFWKTFTSC) was purchased from Sigma-Aldrich (St. Louis, MO, USA). Synthetic A $\beta_{40}$ (DAEFRHDSGYEVHHQKLVFFAEDVGSNKGAIIGLMVGGVV) and A $\beta_{42}$ (DAEFRHDSGYEVHHQKLVFFAEDVGSNKGAIIGLMVGGVVIA) were obtained from Peptide Institute, Inc. (Osaka, Japan) that were purified by highperformance liquid chromatography (HPLC) using YMC Pack ODS-A (YMC CO., LTD., Kyoto, Japan) and Agilent ZORBAX 300SB-C18 columns (Agilent, Santa Clara, CA, USA), respectively. HEPES [2-(4-(2-hydroxyethyl)piperazin-1-yl)ethanesulfonic acid] was purchased from SigmaAldrich. The buffered solution was prepared in doubly distilled water $\left[\mathrm{ddH}_{2} \mathrm{O}\right.$; a Milli-Q Direct 16 
system (18.2 M $\Omega \cdot \mathrm{cm}$; Merck KGaA, Darmstadt, Germany)]. Trace metal contamination was removed from all solutions used for experiments by treating with Chelex (Sigma-Aldrich) overnight. The concentrations of peptides were determined by an Agilent $8453 \mathrm{UV}-\mathrm{V}$ is spectrophotometer. The secondary structures of SST were analyzed by a JASCO-815 150-L CD spectropolarimeter [Jasco Inc., Tokyo, Japan; KAIST Analysis Center for Research Advancement (KARA), Daejeon, Republic of Korea]. The absorbance and fluorescence values were determined by a SpectraMax M5 microplate reader (Molecular Devices, Sunnyvale, CA, USA) and a HORIBA QuantaMaster QM 400 spectrophotometer (HORIBA, Kyoto, Japan; KARA). Images gained through gel/Western blot were visualized by a ChemiDoc MP imaging system (Bio-Rad, Hercules, CA, USA). Live-cell imaging experiments were conducted by a ZEISS ApoTome2.0 (Carl ZEISS, Oberkochen, Germany). ESI-MS experiments were performed by an Agilent 6530 Accurate Mass Quadrupole Time-of-Flight (Q-TOF) mass spectrometer with an ESI source (Agilent). Morphologies of $A \beta$ aggregates produced from aggregation experiments were taken on a Tecnai F20 transmission electron microscope (FEl Company, Eindhoven, Netherlands; KARA). Confocal microscopic images were taken by a Zeiss LSM 880 (Carl ZEISS; KARA). Detailed experimental procedures are described in the Supplementary Information.

\section{Acknowledgments}

This work was supported by the National Research Foundation of Korea (NRF) grant funded by the Korean government [NRF-2017R1A2B3002585 (M.H.L.); NRF-2021R1A2C3012159 (S.H.L.)]; the Basic Science Research Program through the NRF funded by the Ministry of Education (NRF-2019R1A6A1A10073887) (M.H.L.); the KAIST Advanced Institute for Science-X (KAIX) Challenge (M.H.L.). J.H. thanks the Global Ph.D. fellowship program for support through the NRF funded by the Ministry of Education (NRF-2019H1A2A1073754).

\section{Author contributions}

J.H. and M.H.L. designed the research. J.H. performed the spectroscopic measurements (UVVis, fluorescence, and CD), ESI-MS, docking studies, TEM, biochemical assays, and cell studies with data analysis. E.N. contributed to immunocytochemistry studies. J.Y., T.Q., Y.L., and S.-H.L. conducted the GRABsst studies and interpreted the data. J.H., E.N., and M.H.L. wrote the manuscript with input from all authors.

Competing financial interests. The authors declare no competing financial interests. 


\section{References}

1. Lemoine, D. et al. Ligand-gated ion channels: new insights into neurological disorders and ligand recognition. Chem. Rev. 112, 6285-6318 (2012).

2. Ng, J., Papandreou, A., Heales, S. J. \& Kurian, M. A. Monoamine neurotransmitter disorders-clinical advances and future perspectives. Nat. Rev. Neurology 11, 567-584 (2015).

3. Jacob, T. C., Moss, S. J. \& Jurd, R. GABA ${ }_{A}$ receptor trafficking and its role in the dynamic modulation of neuronal inhibition. Nat. Rev. Neurosci. 9, 331-343 (2008).

4. Dorsam, R. T. \& Gutkind, J. S. G-protein-coupled receptors and cancer. Nat. Rev. Cancer 7, 79-94 (2007).

5. Hyman, S. E. Neurotransmitters. Curr. Biol. 15, R154-R158 (2005).

6. Francis, P. T. The interplay of neurotransmitters in Alzheimer's disease. CNS Spectr. 10, 6-9 (2005).

7. $\mathrm{Xu}, \mathrm{Y}$. et al. Neurotransmitter receptors and cognitive dysfunction in Alzheimer's disease and Parkinson's disease. Prog. Neurobiol. 97, 1-13 (2012).

8. Kepp, K. P. Bioinorganic chemistry of Alzheimer's disease. Chem. Rev. 112, 5193-5239 (2012).

9. Savelieff, M. G. et al. Development of multifunctional molecules as potential therapeutic candidates for Alzheimer's disease, Parkinson's disease, and amyotrophic lateral sclerosis in the last decade. Chem. Rev. 119, 1221-1322 (2019).

10. Kashyap, G. et al. Synapse loss and progress of Alzheimer's disease - a network model. Sci. Rep. 9, 6555 (2019).

11. Nam, E., Nam, G. \& Lim, M. H. Synaptic copper, amyloid- $\beta$, and neurotransmitters in Alzheimer's disease. Biochemistry 59, 15-17 (2020).

12. DeToma, A. S., Salamekh, S., Ramamoorthy, A. \& Lim, M. H. Misfolded protein in Alzheimer's disease and type II diabetes. Chem. Soc. Rev. 41, 608-621 (2012).

13. Deibel, M. A., Ehmann, W. D. \& Markesbery, W. R. Copper, iron, and zinc imbalances in severely degenerated brain regions in Alzheimer's disease: possible relation to oxidative stress. J. Neurol. Sci. 143, 137-142 (1996).

14. Lee, S. J. C., Nam, E., Lee, H. J., Savelieff, M. G. \& Lim, M. H. Towards an understanding of amyloid- $\beta$ oligomers: characterization, toxicity mechanisms, and inhibitors. Chem. Soc. Rev. 46, 310-323 (2017).

15. Larson, M. E. \& Lesné, S. E. Soluble A $\beta$ oligomer production and toxicity. J. Neurochem. 120, 125-139 (2012). 
16. Forner, S., Baglietto-Vargas, D., Martini, A. C., Trujillo-Estrada, L. \& LaFerla, F. M. Synaptic impairment in Alzheimer's disease: a dysregulated symphony. Trends Neurosci. 40, 347357 (2017).

17. Hung, Y. H., Bush, A. I. \& Cherny, R. A. Copper in the brain and Alzheimer's disease. J. Biol. Inorg. Chem. 15, 61-76 (2010).

18. Kepp, K. P. \& Squitti, R. Copper imbalance in Alzheimer's disease: convergence of the chemistry and the clinic. Coord. Chem. Rev. 397, 168-187 (2019).

19. Faller, P. Copper and zinc binding to amyloid- $\beta$ : coordination, dynamics, aggregation, reactivity and metal-ion transfer. ChemBioChem 10, 2837-2845 (2009).

20. Noy, D. et al. Zinc-amyloid $\beta$ interactions on a millisecond time-scale stabilize non-fibrillar Alzheimer-related species. J. Am. Chem. Soc. 130, 1376-1383 (2008).

21. Faller, P., Hureau, C. \& Berthoumieu, O. Role of metal ions in the self-assembly of the Alzheimer's amyloid- $\beta$ peptide. Inorg. Chem. 52, 12193-12206 (2013).

22. Kepp, K. P. Alzheimer's disease: how metal ions define $\beta$-amyloid function. Coord. Chem. Rev. 351, 127-159 (2017).

23. Han, J. et al. Mechanistic approaches for chemically modifying the coordination sphere of copper-amyloid- $\beta$ complexes. Proc. Natl. Acad. Sci. U. S. A. 117, 5160-5167 (2020).

24. Pratesi, A. et al. DOTA-derivatives of octreotide dicarba-analogs with high affinity for Somatostatin sst $_{2,5}$ receptors. Front. Chem. 5, 8 (2017).

25. Patel, Y. C., Liu, J., Galanopoulou, A. \& Parachristou, C. N. Handbook of Physiology: Section 7: The Endocrine System (Oxford Univ. Press, Oxford, 2001).

26. Gahete, M.D. et al. Expression of somatostatin, cortistatin, and their receptors, as well as dopamine receptors, but not of neprilysin, are reduced in the temporal lobe of Alzheimer's disease patients. J. Alzheimers Dis. 20, 465-475 (2010).

27. Weckbecker, G. et al. Opportunities in somatostatin research: biological, chemical and therapeutic aspects. Nat. Rev. Drug Discov. 2, 999-1017 (2003).

28. Song, Y.-H., Yoon, J. \& Lee, S.-H. The role of neuropeptide somatostatin in the brain and its application in treating neurological disorders. Exp. Mol. Med. 53, 328-338 (2021).

29. Jayasekharan, T., Gupta, S. L. \& Dhiman, V. Binding of $\mathrm{Cu}^{+}$and $\mathrm{Cu}^{2+}$ with peptides: peptides = oxytocin, $\mathrm{Arg}^{8}$-vasopressin, bradykinin, angiotensin-I, substance-P, somatostatin, and neurotensin. J. Mass. Spectrom. 53, 296-313 (2018).

30. Wang, H. et al. Somatostatin binds to the human amyloid $\beta$ peptide and favors the formation of distinct oligomers. eLife 6, e28401 (2017). 
31. Saito, $T$. et al. Somatostatin regulates brain amyloid $\beta$ peptide $A \beta_{42}$ through modulation of proteolytic degradation. Nat. Med. 11, 434-439 (2005).

32. Solarski, M., Wang, H., Wille, H. \& Schmitt-Ulms, G. Somatostatin in Alzheimer's disease: a new role for an old player. Prion 12, 1-8 (2018).

33. Anoop, A. et al. Elucidating the role of disulfide bond on amyloid formation and fibril reversibility of somatostatin-14: relevance to its storage and secretion. J. Biol. Chem. 289, 16884-16903 (2014).

34. Ciesienski, K. L., Haas, K. L. \& Franz, K. J. Development of next-generation photolabile copper cages with improved copper binding properties. Dalton Trans. 39, 9538-9546 (2010).

35. Thordarson, P. Determining association constants from titration experiments in supramolecular chemistry. Chem. Soc. Rev. 40, 1305-1323 (2011).

36. Kocyła, A., Pomorski, A. \& Krężel, A. Molar absorption coefficients and stability constants of Zincon metal complexes for determination of metal ions and bioinorganic applications. J. Inorg. Biochem. 176, 53-65 (2017).

37. Meng, X. et al. Stable H3 peptide was delivered by gold nanorods to inhibit LSD1 activation and induce human mesenchymal stem cells differentiation. Oncotarget 8, 23110-23119 (2017).

38. Kahn, P. C. \& Beychok, S. Far-ultraviolet optical activity of crystals in mulls. I. Cystine. J. Am. Chem. Soc. 90, 4168-4170 (1968).

39. Dharmadana, D., Reynolds, N. P., Dekiwadia, C., Conn, C. E. \& Valéry, C. Heparin assisted assembly of somatostatin amyloid nanofibrils results in disordered precipitates by hindrance of protofilaments interactions. Nanoscale 10, 18195-18204 (2018).

40. Feng, J. et al. A genetically encoded fluorescent sensor for rapid and specific in vivo detection of norepinephrine. Neuron 102, 745-761 (2019).

41. Jing, M., Zhang, Y., Wang, H. \& Li, Y. G-protein-coupled receptor-based sensors for imaging neurochemicals with high sensitivity and specificity. J. Neurochem. 151, 279-288 (2019).

42. Jing, M. et al. An optimized acetylcholine sensor for monitoring in vivo cholinergic activity. Nat. Methods 17, 1139-1146 (2020).

43. Vivian, J. T. \& Callis, P. R. Mechanisms of tryptophan fluorescence shifts in proteins. Biophys. J. 80, 2093-2109 (2001).

44. Vivekanandan, S., Brender, J. R., Lee, S. Y. \& Ramamoorthy, A. A partially folded structure of amyloid-beta(1-40) in an aqueous environment. Biochem. Biophys. Res. Commun. 411, 312-316 (2011). 
45. $\mathrm{Hu}, \mathrm{X}$. et al. Amyloid seeds formed by cellular uptake, concentration, and aggregation of the amyloid-beta peptide. Proc. Natl. Acad. Sci. U. S. A. 106, 20324-20329 (2009).

46. Biancalana, M. \& Koide, S. Molecular mechanism of thioflavin-T binding to amyloid fibrils. Biochim. Biophys. Acta. 1804, 1405-1412 (2010).

47. Beck, M. W. et al. A rationally designed small molecule for identifying an in vivo link between metal-amyloid- $\beta$ complexes and the pathogenesis of Alzheimer's disease. Chem. Sci. 6 , 1879-1886 (2015).

48. Bernstein, S. L. et al. Amyloid- $\beta$ protein oligomerization and the importance of tetramers and dodecamers in the aetiology of Alzheimer's disease. Nat. Chem. 1, 326-331 (2009).

49. Nirmalraj, P. N. et al. Complete aggregation pathway of amyloid $\beta(1-40)$ and (1-42) resolved on an atomically clean interface. Sci. Adv. 6, eaaz6014 (2020).

50. Benilova, I., Karran, E. \& De Strooper, B. The toxic A $\beta$ oligomer and Alzheimer's disease: an emperor in need of clothes. Nat. Neurosci. 15, 349-357 (2012).

51. Mucke, L. \& Selkoe, D. J. Neurotoxicity of amyloid beta-protein: synaptic and network dysfunction. Cold Spring Harb. Perspect. Med. 2, a006338 (2012).

52. Kuragano, M., Yamashita, R., Chikai, Y., Kitamura, R. \& Tokuraku, K. Three-dimensional real time imaging of amyloid $\beta$ aggregation on living cells. Sci. Rep. 10, 9742 (2020).

53. Zhao, Y. et al. Amyloid beta peptides block new synapse assembly by Nogo receptormediated inhibition of T-type calcium channels. Neuron 96, 355-372 (2017). 